\title{
Immunohistochemical Detection of Herpes Simplex Virus-2 (HSV-2) in Cervical Carcinoma among Sudanese Female in Khartoum state - Sudan 2020
}

\author{
Shaza Arbab Mohamed Arbab ${ }^{1 *}$, Ageeb Mohammed Hassan Abdellah ${ }^{2}$, Tarig Mohamed Elfaki Alabbas ${ }^{3}$ \\ ${ }^{1}$ Department of Histopathology, Alneelain University, 52nd St, Khartoum, Sudan \\ ${ }^{2}$ Assistant Professor, Department of Pathology, Elribat National University, Khartoum, Sudan \\ ${ }^{3}$ Academy of Health Science
}

DOI: 1 10.36348/sjpm.2020.v05i07.003 $\quad$ | Received: 20.07.2020 | Accepted: 28.07 .2020 | Published: 30.07 .2020

*Corresponding author: Shaza Arbab Mohamed Arbab

\section{Abstract}

In Sudan, invasive Cervical cancer is the one of the most common causes of death. The Herpes simplex virus ( HSV-2) is second common causes of the invasive cervical cancer, with fraction progress to cervical cancer disease pointing to possible the role of additional risk factors in development of disease which include: host genetic factor and other infection such as HPV-16, for that women should have regular cervical screening test to detect early cervical cancer. Materials \& Methods: This is a retrospective cross sectional study that includes about 75 embedded paraffine wax tissue blocks using immune histochemical stain from patients previously diagnosed as cervical cancer and expression of herpes simplex virus. Details of the patients information taken from medical reports .The analysis done by SPSS. Result: The mean age in this study is 60 with group range between (61-70) years (83.3\%), The Herpes Simplex virus is express only in squamous cell carcinoma. Discussion: The mean age is 60 with age group (61-70) $(\mathrm{n}=5: 20 \%)$ expression of HSV-2 with $(\mathrm{P}=0.136)$, and the expression of $\mathrm{HSV}-2$ with squamous cell carcinoma of tumor type $(\mathrm{n}=6: 10.90 \%)$ with $(\mathrm{P}=$ 0.476), histological grade well differentiated $(\mathrm{n}=6: 11.10 \%)$ with $(\mathrm{P}=0.477)$. Conclusion: The expression of HSV-2 was insignificant in age group. The expression of HSV-2 was insignificant in tumor type squamous cell carcinoma. The expression of HSV-2 was insignificant in histological grade.

Keywords: Herpes Simplex Virus (HSV), Human Papilloma Virus (HPV), Deoxyribonuclic acid (DNA), cervical intraepithelial neoplasia (CIN), Polymerase chain reaction (PCR), Enzyme linked immunesorbent assay (ELISA).

Copyright @ 2020: This is an open-access article distributed under the terms of the Creative Commons Attribution license which permits unrestricted use, distribution, and reproduction in any medium for non-commercial use (NonCommercial, or CC-BY-NC) provided the original author and sources are credited.

\section{INTRODUCTION}

Cervical cancer is the third common cancer in the world in females and fourth leading cancer for death in women. Every year 530,000 cases are diagnosed and 265, 653 deaths occur in the world due to cervical cancer. In Sudan, cervical cancer is the second most prevalent cancer in account $12-16 \%$ of Sudanese female [1]. Approximately $1.6 \%$ of all women will develop cancer of the cervix during their lifetime [2]. Cervical cancer mainly affects countries with low or medium levels of human development, and It's incidence rates vary significantly from country to country [3]. The incidence/prevalence is decreasing in developed countries due to health awareness and regular/systemic cervical cancer screening; some countries using HPV DNA (Human Papilloma Virus) test in addition to Pap tests. This routine screening has reduced the incidence to $70 \%$ in developed countries. However, cervical cancer persists in developing countries that constitute
$85 \%$ of total world cases, despite only $5 \%$ global cancer resources in these countries. The major risk factors associated with cervical cancer are the early onset of sexual intercourse, multiple sexual partners, and/or sexual contact with promiscuous partners [4]. The disease is composed of several pathological stages ranging from cervical intraepithelial neoplasia (CIN) to invasive squamous carcinoma. Substantial evidence suggests that CIN is a precursor of invasive cervical carcinoma. Early changes in cervix (e.g. squamous intraepithelial lesions) can be detected years before malignancy by screening tests like Pap smear, and such primary screening has resulted in declined incidences of cervical cancer in several countries over the past 30 years [3]. Due to It's characteristics of being sexually transmitted, cervical cancer is deemed as sexually transmitted cancer. Indeed, recent changes in sexual behavior have led to increase in risk of HPV infection, 
thereby elevating cervical cancer incidences in several eastern European countries and former Soviet states [5].

In addition to HPV, other factors are postulated to play a role in the development of cervical cancer. These include smoking, human cytomegalovirus, human herpes virus 6, human immunodeficiency virus, and HSV-2. HSV-2 is spread primarily by sexual contact, and therefore the risk factors are similar to those of other sexually transmitted diseases [6]. A recent epidemiological study suggested that a biological interaction between HSV-2 and HPV16 or HPV-18 occurs during the development of cervical carcinoma. Also suggested that infection with both viruses is a significant risk but that infection with one or the other is not nearly as significant. Several independent epidemiological studies have also linked HSV-2 infections to an increased incidence of cervical carcinoma. Unfortunately, these studies do not include the contribution by the risk associated with HPV infection. In contrast, found that there is no correlation between HSV-2 and cervical cancer [7]. Many infectious agents are established as the etiological agents in various cancers in humans constituting approximately $15 \%$ of all cancers [8]. Human Papilloma Virus (HPV) is the proved major etiological factor in etiopathogenesis of cervical cancer. HPV is necessary but alone is not sufficient to cause cervical cancer as there is a long latent period between the infection, and manifestation of cervical cancer and all women infected with HPV does not have cervical cancer. Hence, there are some co-factors that have synergetic action with HPV in causing cervical cancer. The co-factors proved by epidemiological studies are smoking, nicotine, long-term use of oral contraceptives, use of intrauterine contraceptive device, lifestyle as early initiation of sexual life/multiple sexual partners, young age at full term pregnancy, multiple full-term pregnancy, low socioeconomic status, diet low in antioxidants, genetic predisposition and decreased immunity. In addition, the sexual transmitted diseases like Chlamydia trachomatis, Gardenella vaginitis, etc. has role in cervical cancer $[9,8,10]$. In this article, the role of different viruses in the pathogenesis of cervical cancer is highlighted. HSV-2 that is related with cervical cancer than HSV1. It was the first virus thought as the primary etiological factor for cervical cancer in 1960 and 1970. It is transmitted by sexual contact and proved to have synergetic role with HPV in causing CIN/cancer. Various studies of HSV-2 regarding DNA study, viral load, serological study and co-infection with HPV has been done to reveal the role of HSV-2 or synergetic action with HPV in the cervix [11]. The HSV-2 DNA, serological positivity and viral load increased from cervicitis to CIN to cancer (both squamous cell carcinoma and adenocarcinoma). HSV-2 infection or co-infection with HPV by seroepidemiological studies is strongly higher in CIN and cervical cancer than in healthy women [12]. However PCR results of HSV-2 DNA in cervical cancer is variable. However, still the issue is controversial and unclear ranging from no association to synergetic role with HPV in causing severe cervical lesions. Some study also states that cervical cancer may predispose to HSV-2 infection [11]. The mechanism of action of HSV-2 in causing CIN/cancer are described in the literature; "Hit and Run" hypothesis stating that the HSV-2 take part in some phase of cervical carcinogenesis and does not require retention of $\mathrm{HSV}$ viral genes, hence HSV-2 is not detected consistently in all cervical biopsy of CIN/cancer suggesting $\mathrm{HSV}$ is necessary for initial transformation of cells and not for its progression. HSV-2 infection in cervical cells with or without HPV infection leads to mutation and genetic rearrangements which has growth regulatory mechanism [13]. In HPV-infected cells, the HSV-2 mutation is more detrimental in which HPV E6 inactivates P53 protein, causes increased abnormal proliferation of HSV-2 mutagenized epithelial cells. Thus, HSV-2 acts as a cofactor in the progression of CIN to cervical cancer by inducing DNA damage and chromosomal abnormalities in cervical epithelial cells that are latently infected with HPV [12]. The other mechanism described are; ulcer caused by HSV-2 infection facilitates entry of HPV and reach basal cells, herpetic inflammation interfere with effective immune response against HPV infection by suppressing $\mathrm{T}$ helper cell-mediated immune response, induce production of nitric acid that may result in cellular DNA damage in HPV-infected cells and increase risk of carcinogenesis, HSV-2 infection increase integration of HPV DNA into infected host cell genome, enhances replication of HPV and thus facilitates progression of HPV infection to cervical neoplasia. HSV-2 is associated with squamous cell carcinoma, adenocarcinoma and adenosquamous carcinoma of the cervix [14]. HSV-2 infection is detected by RT-PCR, PCR, in-situ hybridization techniques and serological methods of which RT-PCR is more reliable. The use of immunoglobulin $A$ than immunoglobulin $\mathrm{G}$ as a marker for the presence of HSV-2 correlates with various stages of cervical cancer [15].

\section{MATERIALS \& METHODS}

This study performed in Maternity Hospital (Omdurman - Sudan) during period from October to December 2019, Seventy five Sudanese females previously diagnosed as cervical carcinoma, Section measure 4 micron from block was cut using a rotary microtome the cut section will float in $70 \%$ ethanol and water bath at 40c respectively, after floatation, section will mount on a super frost positive charge glass slide. Then incubate at room temperature (RT) over night, then transferred to dry oven at $50 \mathrm{c}$ for $24 \mathrm{hrs}$. The slide will then let cool at RT and then stain immunohistochemically. Paraffin section from deparaffinized in two changes of xylene for 10 minutes and then rehydrate in ethanol as follow: sections placed in two changes of absolute ethanol for 5 minutes. $90 \%$ ethanol is placed for 3 minutes, and then placed in $70 \%$ 
ethanol for 2 minutes. Then washed in distilled water for 2 minutes and then washed two times in buffer.

Antigens is retrieved in preheated water bath at $95 \mathrm{c}$ in glasses coplin jar in steamer contain $1 \mathrm{ml}$ target retrieval buffer (TRB) and $50 \mathrm{ml}$ distilled water (D.W) of $\mathrm{PH} 9$ for 40 minutes. Slide washed in phosphate buffer saline (PBS) of PH 7.4 for 3-5 minutes. Endogenous peroxidase activity blocked in hydrogen peroxide block for 10-15 minutes. Slide then washed in (PBS) for 3-5 minutes, then dried for a few seconds and wipe around the sections with tissue paper and encircle round the tissue using DAKO pen. Specific primary antibody is applied to each section for 30 minutes Slide the washed in (PBS) for 3-5 minutes. Secondary antibody placed on each section for 30 minutes at room temperature and then washed in (PBS) for 10 minute.

Horse radish peroxidase (HRP) is placed on each section for 30 minutes at room temperature and then washed in (PBS) for 10 minutes. One drop from 3.3 diaminobenzidine tetra hydrochloride (DAB) plus chromogen add to $2 \mathrm{ml}$ of (DAB) plus substrate, then mixed by swirling and applied to tissue for 10 minutes. Slide is rinsed in running tap water (RTW) for 5 minutes.

Counter stain in mayer's hematoxylin for 1 minute, then blue in RTW for 5-10 minute, dehydrate in grades of ethanol, cleared in xylene and mounted in disterene plasticizer (polystyrene) and xylene (DPX), the stain samples is evaluated based on the number of stain cells and the densities of staining.

\section{RESULT}

The study included paraffin wax tissue blocks from 75 women had cervical cancer, their age is range between 33 years and 77 years with mean of 60 years. Age is divided in to 5 age groups as follows: (33-40) $(\mathrm{n}=13: 17.30 \%),(41-50) \quad(\mathrm{n}=13: 17.3 \%),(51-60)$ $(n=10: 13.3 \%),(61-70) \quad(n=25: 33.3 \%)$ and $(71-80)$ $(\mathrm{n}=14: 18.6 \%)$. The most common age group was $(61-$ 70) $(n=25: 80 \%)$ As shown in (Table-1).
Concerning the tumor types, the results was as follows: Squamous cell carcinoma found in (55: 71.0 $\%)$, adenocarcinoma seen in $(17: 25.0 \%)$ and choriocarcinoma was seen in $(3: 4.0 \%)$. The common tumor type is squamous cell carcinoma. As shown in (Figure-1).

About the histological grades of the tumors, well differentiated carcinoma was found in cases (54: $70.0 \%$ ), moderately differentiated (3: 04.00\%) and poorly differentiated (18: $26.0 \%)$, the most common histological grade is well differentiated. As shown in (Table-2).

Immunoexpression of Herpes simplex virus -2 (HSV-2) was positive in one case among age group of $(35-41)(n=1: 16.7 \%)$ and in 5 cases of age group (6170) $(n=5: 83.3 \%)$, but negative in all other groups with $(\mathrm{P}=0.136)$. As shown in (Table-3).

Expression of virus was seen only in 6 sample of Squamous cell carcinoma $(n=6: 10.90 \%)$ not seen in adenocarcinoma and choriocarcinoma, with $(\mathrm{P}=0.476)$. As shown in (Table-4).

In assessment of immune expression with the histological grade the immunoexpression of Herpes simplex virus -2 (HSV-2) was positive in only 6 cases of well differentiated carcinoma $(n=6: 11.10 \%)$, with $(\mathrm{P}=0.477)$. As shown in $($ Table-5).

Table-1: Age group

\begin{tabular}{|l|l|l|}
\hline Age group & Frequency & Percentage \\
\hline 35-40 years & 13 & $17.30 \%$ \\
\hline 41-50 years & 13 & $17.30 \%$ \\
\hline 51-60 years & 10 & $13.30 \%$ \\
\hline 61-70 years & 25 & $33.30 \%$ \\
\hline 71-78 years & 14 & $18.60 \%$ \\
\hline Total & $\mathbf{7 5}$ & $\mathbf{1 0 0 \%}$ \\
\hline \multicolumn{3}{|c|}{$* \mathbf{P}=\mathbf{0 . 0 5}$}
\end{tabular}

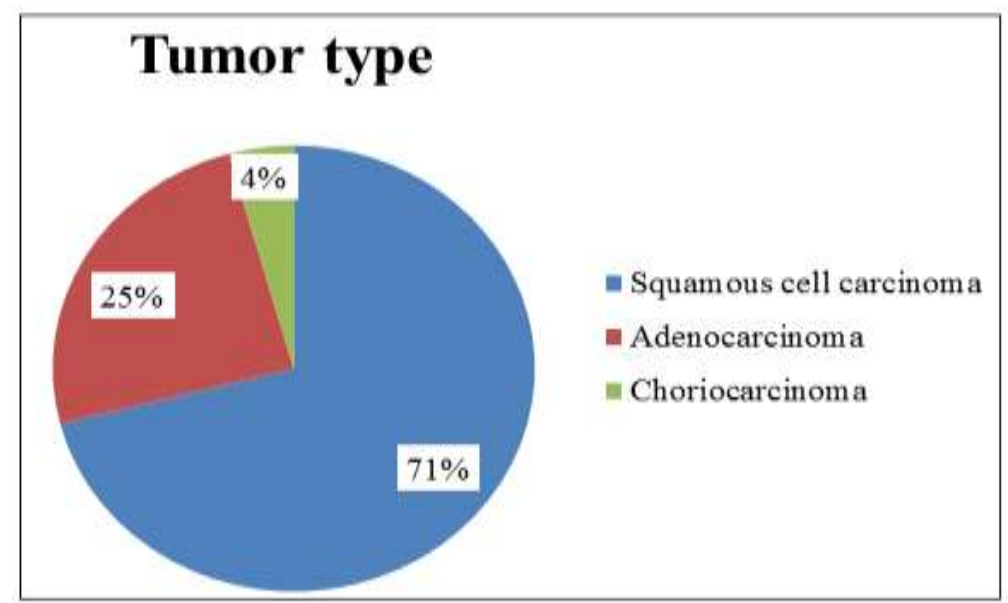

Fig-1: Tumor type $\mathbf{P}=>\mathbf{0 . 0 5}$ 
Table-2: Histological grade

\begin{tabular}{|l|l|l|}
\hline Tumor grades & Frequency & Percentage \\
\hline Well differentiated & 54 & $70.00 \%$ \\
\hline Moderately differentiated & 3 & $04.00 \%$ \\
\hline Poorly differentiated & 18 & $26.00 \%$ \\
\hline Total & $\mathbf{7 5}$ & $\mathbf{1 0 0 \%}$ \\
\hline \multicolumn{2}{|l}{} \\
\multirow{2}{|l}{$\mathbf{P}=\mathbf{> 0 . 0 5}$}
\end{tabular}

Table-3: Immunoexpression of Herpes simplex virus -2 (HSV-2) according to age groups

\begin{tabular}{|l|l|l|l|}
\hline Age group & Negative & Positive & Total \\
\hline \multirow{3}{*}{$35-40$ years } & 12 & 1 & 13 \\
\cline { 2 - 4 } & $92.30 \%$ & $7.70 \%$ & $100.00 \%$ \\
\hline \multirow{2}{*}{ 41-50 years } & 13 & 0 & 13 \\
\cline { 2 - 4 } & $100.00 \%$ & $0.00 \%$ & $100.00 \%$ \\
\hline $51-60$ years & 10 & 0 & 10 \\
\cline { 2 - 4 } & $100.00 \%$ & $0.00 \%$ & $100.00 \%$ \\
\hline 61-70 years & 20 & 5 & 25 \\
\cline { 2 - 4 } & $80.00 \%$ & $20.00 \%$ & $100.00 \%$ \\
\hline $71-78$ years & 14 & 0 & 14 \\
\cline { 2 - 4 } & $100.00 \%$ & $0.00 \%$ & $100.00 \%$ \\
\hline Total & 69 & 6 & 75 \\
\cline { 2 - 4 } & $92.00 \%$ & $8.00 \%$ & $100.00 \%$ \\
\hline
\end{tabular}

Fisher's exact test $\mathrm{P}=0.136^{*}$

$* \mathrm{P}=>0.05$ that's considered as statistically insignificant.

Table-4: Immunoexpression of Herpes simplex virus -2 (HSV-2) and tumor type

\begin{tabular}{|l|l|l|l|}
\hline Histological grades & Negative & Positive & Total \\
\hline Squamous cell carcinoma & 49 & 6 & 55 \\
\cline { 2 - 4 } & $89.10 \%$ & $10.90 \%$ & $100.00 \%$ \\
\hline Adenocarcinoma & 17 & 0 & 17 \\
\cline { 2 - 4 } & $100.00 \%$ & $0.00 \%$ & $100.00 \%$ \\
\hline Choriocarcinoma & 3 & 0 & 3 \\
\cline { 2 - 4 } & $100.00 \%$ & $0.00 \%$ & $100.00 \%$ \\
\hline \multirow{2}{*}{ Total } & 69 & 6 & 75 \\
\cline { 2 - 4 } & $92.00 \%$ & $8.00 \%$ & $100.00 \%$ \\
\hline
\end{tabular}

$* \mathrm{P}=>0.05$ that's considered as statistically insignificant.

Table-5: Immunoexpression of Herpes simplex virus -2 (HSV-2) and histological grade

\begin{tabular}{|l|l|l|l|}
\hline Histological grades & Negative & Positive & Total \\
\hline \multirow{3}{*}{ Well differentiated } & 48 & 6 & 54 \\
\cline { 2 - 4 } & $88.90 \%$ & $11.10 \%$ & $100.00 \%$ \\
\hline Moderately differentiated & 3 & 0 & 3 \\
\cline { 2 - 4 } & $100.00 \%$ & $0.00 \%$ & $100.00 \%$ \\
\hline \multirow{2}{*}{ Poorly differentiated } & 18 & 0 & 18 \\
\cline { 2 - 4 } & $100.00 \%$ & $0.00 \%$ & $100.00 \%$ \\
\hline Total & 69 & 6 & 75 \\
\cline { 2 - 4 } & $92.00 \%$ & $8.00 \%$ & $100.00 \%$ \\
\hline
\end{tabular}

*Fisher's exact test $\mathrm{P}=0.477$

$* \mathrm{P}=>0.05$ that's considered as statistically insignificant 


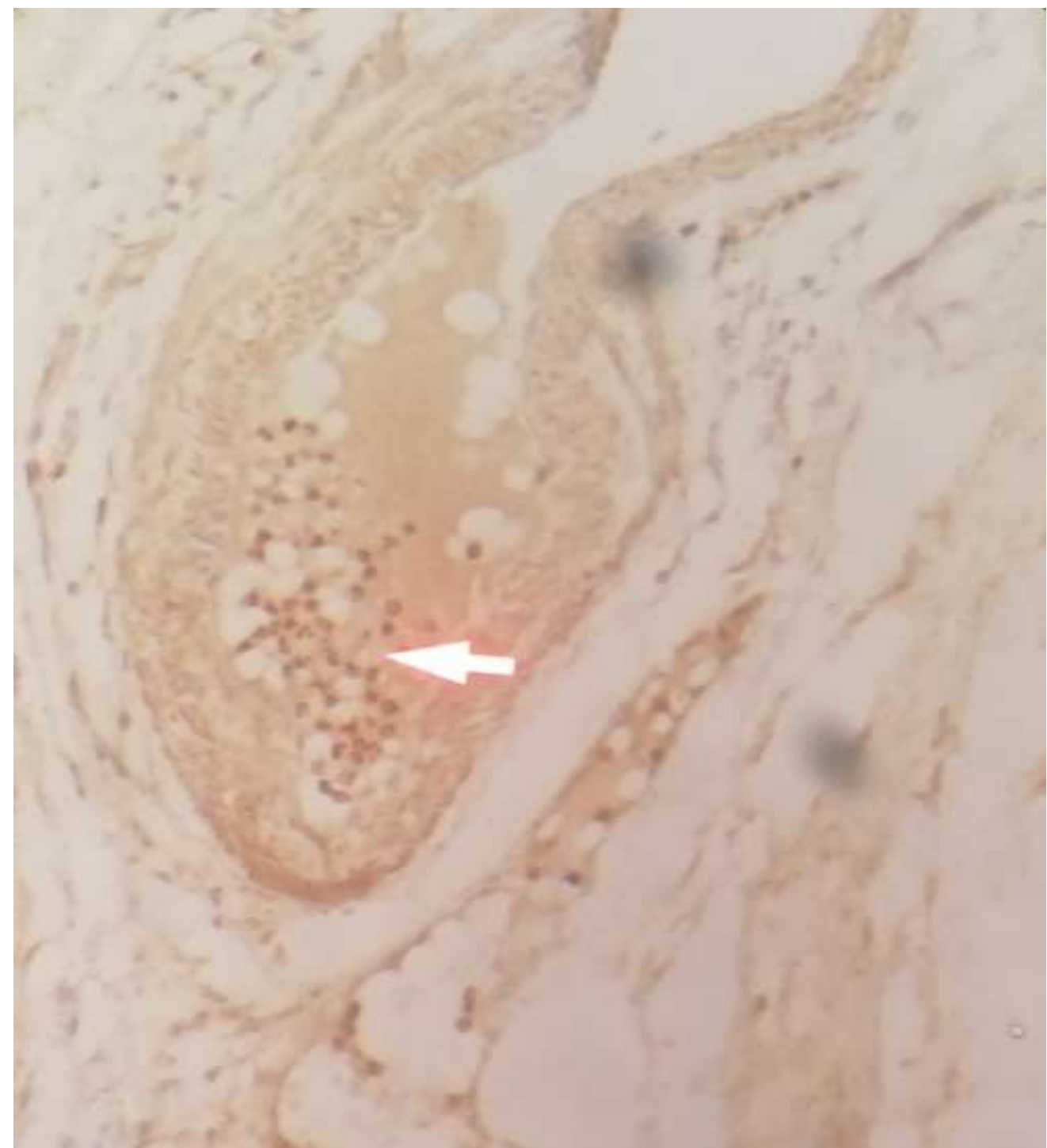

Fig-2: Expression of herpes simplex virus HSV-2 in section

\section{DISCUSSION}

Cervical cancer is most common malignancy in women, with presentation in elderly female and the mean age of in this study is 60 with group range between (61-70) years $(20 \%)$, The $(\mathrm{P}=0.136)$ that's insignificant, This study is agree with the Chattopadhyay BMC Cancer et al (2015), no significant difference in age group was observed between cases and controls $(\mathrm{P}=0.271)$.

Also this study is Dis agree with the JARC et al., [16], which showed the expression of HSV-2 was significant $(\mathrm{P}=0.001)$ among the case patients with squamous cell invasive cervical cancer with median age group 52 (24-74).

In this study, herpes simplex virus are express in epithelial tissue in the squamous cell carcinoma in 6 $(10.90 \%)$ and adenocarcinoma are 0 , with $(\mathrm{P}=0.476)$ that's statistically insignificant, this findings is agree with the American association for cancer research [17], diagnosed with invasive squamous cell cervical cancer the study was insignificant at the $(\mathrm{P}=>0.05)$. Not agree with Kjaerl, S. K et al., [18], the HSV-2 is significantly higher in Greenlandic women with cervical cancer $(\mathrm{P}=$ $<0.0001)$, and in Denmark are $(\mathrm{P}=<0.0001)$.

Also this study is disagree with Salcedo Mde M et al., [19] in the expression of herpes simplex virus in invasive squamous cell carcinoma of uterine cervix cancer, it was significant $(\mathrm{P}=<00.01)$, not acceptable with the $\mathrm{Li}$ et al., [20], were investigated by the immunohistochemical method expression of HSV-2 in squamous intraepithelial lesion and cervical cancer was significant $(\mathrm{P}=00.01)$. Other study not agree with this study [16], the association of HSV-2 with cervical neoplasia (invasive cervical carcinoma and/or carcinoma in situ) were identified significant $(\mathrm{P}=0.01)$.

Our finding also not agree with the study of, Christine Johnston et al., [21], invasive/ in situ squamous cell carcinoma of cervical cancer for expression of HSV-2 was significant $(\mathrm{P}=<0.001)$. 
The current study, there was no statistical association between the histological grade well differentiated and expression of herpes simplex virus-2 $(\mathrm{P}=0.477)$, Our finding this study agree with Afsana $\mathrm{S}$ et al., [22], WD histopathological grade with $\mathrm{p}$ value $(\mathrm{P}=0.289)$. Agree with Elizabeth et al., [23], diagnosed as well differentiated squamous cell carcinoma it was no significant with $(\mathrm{P}=0.474)$. Disagree with Kalyani Raju et al., [24], there was statistically significant with grade of disease WDSCC $(\mathrm{P}=0.001)$.

\section{CONCLUSION}

- The mean age of patients diagnosed with cervical cancer is 60 years.

- The major type of the cervical cancer is squamous cell carcinoma samples among Sudanese female.

- There was insignificant association of HSV-2 with age group of cervical cancer.

- There was insignificant association of HSV-2 with tumor type squamous cell carcinoma of cervical cancer.

- The expression of HSV-2 is in significant with histological grade well differentiated.

\section{RECOMMENDATIONS}

- Increase sample size.

- Correlate the immunochemical method with molecular.

- Molecular biology for finding DNA /HSV-2 genome.

- $\quad$ PCR \& In situ hybridization.

- Immunofluorescence assay.

- Glycoprotien gG-2 ELISAs for viral infected cell protein (ICP) 8 measured by II/I assay.

\section{REFERENCES}

1. Mohamed, K. E. H., \& Ashmeig, A. A. A. (2017). Cervical cancer: Our experience in Sudan. Cancer Research.

2. Ali, M. A., McWeeney, D., Milosavljevic, A., Jurka, J., \& Jariwalla, R. J. (1991). Enhanced malignant transformation induced by expression of a distinct protein domain of ribonucleotide reductase large subunit from herpes simplex virus type 2. Proceedings of the National Academy of Sciences, 88(18), 8257-8261.

3. Anthony, D. D., Wentz, W. B., Reagan, J. W., \& Heggie, A. D. (1989). Induction of cervical neoplasia in the mouse by herpes simplex virus type 2 DNA. Proceedings of the National Academy of Sciences, 86(12), 4520-4524.

4. Aurelian, L., Kessler, I. I., Rosenshein, N. B., \& Barbour, G. (2004). Herpes simplex virus 2 and cervical cancer. Clin Dermatol. 2:90-99.

5. Barber, H. R. K. (2008). Cancer of the cervix, 212-268. In Manual of gynecologic oncology, 2nd ed. J. B. Lippincott Co., Philadelphia.
6. Bejcek, B., \& Conley, A. J. (1986). Genomic rearrangement in the mammalian cell DNA homologous to the herpes simplex viruses in HSV2 mtrII induced transformed cells. Virology, 154, 42-55.

7. Brandt, C. R., Galloway, D. A., \& McDougall, J. K. (2007). Synergistic interactionbetweenHPV18sequences, herpes simplex virus infections and chemical carcinogens. Cancer Cells. 5:179-186.

8. Marinho-Dias, J., \& Sousa, H. (2013). Cytomegalovirus infection and cervical cancer: from past doubts to present questions. Acta medica portuguesa, 26(2), 154-160.

9. Alibek, K., Karatayeva, N., \& Bekniyazov, I. (2012). The role of infectious agents in urogenital cancers. Infectious agents and cancer, 7(1), 1-7.

10. Nobel Prize. (2008). The Nobel prize in Physiology or medicine (The Nobel prize in Physiology or medicine).

11. Clements, G. B., \& Subak-Sharpe, J. H. (1988). Herpes simplex virus type 2 establishes latency in the mouse footpad. Journal of general virology, 69(2), 375-383.

12. Conner, J., Cooper, J., Furlong, J., \& Clements, J. B. (1992). An autophosphorylating but not transphosphorylating activity is associated with the unique $\mathrm{N}$ terminus of the herpes simplex virus type 1 ribonucleotide reductase large subunit. Journal of virology, 66(12), 7511-7516.

13. Corbino, N., Guglielmino, S., Petrina, M., Tempera, G., Ciravolo, L., \& Cianci, A. (1989). The role of anti-herpes specific serum IgA levels as a marker in cervical oncogenesis. European Journal of Gynaecological Oncology, 10(2), 103108.

14. Cory, I., \& Spear, P. G. (1986). Identification of herpes simplex virus 2 sequences in cancer of the cervix. N. Engl. J. Med, 314, 686-691.

15. De Sanjose, S., Munoz, N., Bosch, F. X., Reimann, K., Pedersen, N. S., Orfila, J., ... \& Lette, I. (1994). Sexually transmitted agents and cervical neoplasia in Colombia and Spain. International Journal of Cancer,56(3), 358-363.

16. Lehtinen, M., Koskela, P., Jellum, E., Bloigu, A., Anttila, T., Hallmans, G., ... \& Hakama, M. (2002). Herpes simplex virus and risk of cervical cancer: a longitudinal, nested case-control study in the nordic countries. American journal of epidemiology, 156(8), 687-692.

17. Daling, J. R., Madeleine, M. M., McKnight, B., Carter, J. J., Wipf, G. C., Ashley, R., ... \& Galloway, D. A. (1996). The relationship of human papillomavirus-related cervical tumors to cigarette smoking, oral contraceptive use, and prior herpes simplex virus type 2 infection. Cancer Epidemiology and Prevention Biomarkers, 5(7), 541-548.

18. Kjaer, S. K., de Villiers, E. M., Cağlayan, H., Svare, E., Haugaard, B. J., Engholm, G., ... \& 
Vestergaard, B. F. (1993). Human papillomavirus, herpes simplex virus and other potential risk factors for cervical cancer in a high-risk area (Greenland) and a low-risk area (Denmark)-a second look. British journal of cancer, 67(4), 830837.

19. Salcedo, M. D. M. B. P., Silveira, G. P. G. D., \& Zettler, C. G. (2008). Immunohistochemical expression of p16 and herpes simplex virus type 2 in squamous intraepithelial lesions and cervical cancer. Revista Brasileira de Ginecologia $e$ Obstetrícia, 30(2), 61-66.

20. Li, S., \& Wen, X. (2017). Seropositivity to herpes simplex virus type 2 , but not type 1 is associated with cervical cancer: NHANES (19992014). BMC cancer, 17(1), 726.

21. Johnston, C., \& Corey, L. (2016). Current concepts for genital herpes simplex virus infection: diagnostics and pathogenesis of genital tract shedding. Clinical microbiology reviews, 29(1), 149-161.

22. Shah, A., Jena, N. K., \& Shukla, P. (2018). Role of histopathological differentiation as a prognostic factor for treatment response in locally advanced squamous cell carcinoma cervix patients. Indian Journal of Medical and Paediatric Oncology, 39(3), 282.

23. Kidd, E. A., Spencer, C. R., Huettner, P. C., Siegel, B. A., Dehdashti, F., Rader, J. S., \& Grigsby, P. W. (2009). Cervical cancer histology and tumor differentiation affect $18 \mathrm{~F}-$ fluorodeoxyglucose uptake. Cancer: Interdisciplinary International Journal of the American Cancer Society, 115(15), 3548-3554.

24. Kalyani, R., Raghuveer C. V., \& Sheela, S. R. (2019). Clinicopathological correlation of invasive squamous cell carcinoma of uterine cervix: A cross-sectional study. 6(11):3443-3451. 